\title{
Influence of separator control on the characteristics of severe slugging flow
}

\author{
Luo Xiaoming*, He Limin, Liu Xinye and Lü Yuling \\ College of Pipeline and Civil Engineering, China University of Petroleum, Qingdao, Shandong 266580, China \\ (C) China University of Petroleum (Beijing) and Springer-Verlag Berlin Heidelberg 2014
}

\begin{abstract}
Due to the special structure of offshore multiphase pipes, it is easy for severe slugging to occur in the riser at low gas-liquid velocity. Violent pressure fluctuations and dramatic changes of flow rate are the main characteristics of severe slugging, leading to the risk of serious damage. In this paper, the separator control is adopted to accurately control the separator liquid level and pressure under severe slugging flow conditions. This indicates that the separator liquid level control alone does not have a significant impact on the upstream flow, but it is beneficial for normal operation and pressure control of the separator. As the separator pressure increases, the peak pressure in the riser apparently diminishes, and the amplitude of pressure fluctuation gradually decreases, which means that severe slugging is inhibited. During the slug blowing out, the gas/liquid slipping in the riser intensifies. The long gas plug quickly flows through the riser, and then tends to morph into short and slowly flowing gas bubbles. The elimination effect of the pressure control strategy on severe slugging is related to the relative rate of the superficial gas/liquid flow.
\end{abstract}

Key words: Multiphase flow, severe slugging, separator control, riser

\section{Introduction}

In offshore oil and gas production, submarine pipelines and riser systems are used to transport oil and gas from the wellhead to the platform. It is easy for severe slugging to occur in the riser at low gas-liquid velocity. The situation becomes worse as the oil exploitation depth increases. The severe slugging may cause serious damage including overflow or stop-flow in separators due to the dramatic flow changes, damage to the pipelines and the platform because of the vibration, and a decrease in oil and gas production as the wellhead backpressure increases (Li et al, 2005; Liu et al, 2007; Storkaas and Skogestad, 2002; Storkaas et al, 2003).

In recent years, severe slugging has been attracting increasing attention as oil and gas exploration and production expands to deepwater areas. Several researchers investigated the control and elimination of severe slugging based on the slug formation mechanism and flow characteristics. Typical severe slugging can be generally divided into four stages: slug formation, slug production, blowout, and liquid fallback (Zhao et al, 2004; Sun et al, 2004; Wang et al, 2005; Wang and Guo, 2006). Its characteristic parameters change periodically. There are four types of elimination methods in summary. The first one is to reduce the hydrostatic pressure by decreasing the slug length, such as the air-lift method (Jansen, 1990; Meng and Zhang, 2001; Sarica and Tengesdal,

*Corresponding author: email: luo-xiaoming@163.com

Received September 8, 2013
2000; Tengesdal et al, 2005), bypass method (Barbuto, 1995; Ma et al, 2010), pump method (Johal, 1997; Lv et al, 2011) and the foam method (Hassanein and Fairhurst, 1988). The second one increases the gas pressure in the pipe before the riser, using the throttling method (Schmidt et al, 1979; Henriot, 1999; Havre and Dalsmo, 2001; Godhavn et al, 2005) and the separator control method (Hollenberg et al, 1995; Kovalev et al, 2003) as examples. The third one changes the flow pattern at the bottom of the riser to eliminate the severe slugging formation, for example, the perturbation method (Almeida and Goncalves, 1999; Almeida et al, 2000). The last method is realized by transporting liquid and gas independently after underwater separation (Kaasa, 1990; Song and Kouba, 2000). Theoretically, all the methods above can eliminate severe slugging. However, due to the tough submarine conditions and the limitations of underwater operation, only the throttling method is applied in practice. Throttling makes the whole system pressurized, which leads to increasing wellhead back pressure and a decreasing oilgas production rate. Separator control is becoming a potential method to inhibit severe slugging. Recent studies focused just on how to improve the separator operation to reduce the effects of severe slugging on the separation system instead of synthetically analyzing the multiphase flow characteristics such as pressure and liquid holdup caused by pressure and liquid level control in the separator. This paper focuses on the study of flow characteristics in severe slugging based on the separator control and explores the interrelationship between the separator control and the upstream multiphase flow 
characteristics.

\section{Experimental systems}

The experimental system consisted of gas-liquid power and metering units, experimental pipelines, a gas-liquid separator, and a system for measuring multiphase flow characteristics, as shown in Fig. 1. The liquid power supply and metering unit included a liquid tank, a centrifugal pump, a Micromotion mass flowmeter and Swagelok regulation valves. The gas power and metering unit was composed of an AtlasCopo screw compressor, a gas buffer tank, a Yokogawa orifice flowmeter and Swagelok regulating valves. The three parts of the experimental pipelines included a 68.1$\mathrm{m}$ long horizontal pipe, a 26.1-m long decline pipe with a $4^{\circ}$ downward angle, and a vertical pipe with a height of 7.7 $\mathrm{m}$. The pipes were made of stainless steel. Each of the three parts had a 4.0-m long transparent polymethylmethacrylate pipe section. The inner diameter of all the pipes was 51.0 $\mathrm{mm}$. The gas-liquid separation system was comprised of a vertical gas-liquid separator, a magnetic flap level gauge, a Rosemount differential pressure transmitter, Fisher ET control valves, a PSL electric actuator and a PID intelligent regulate controller.

Five Keller PA23 pressure transmitters (P1-P2 in Fig. 1) with a frequency of $5 \mathrm{kHz}$ were installed to acquire pressure information in order to study pressure fluctuation characteristics. Their accuracy, repeatability and temperature stability met the experimental requirements. The liquid holdup was tested by two groups of self-made annular conductance probes (Luo et al, 2009) located at the same position as P3 and P4 installed. A data acquisition board, NI PCI-6229, connected in the DIFF pattern was used for data acquisition, and its sampling frequency was $1 \mathrm{kHz}$. The self-adaptive filtering method was chosen to filter signals. The experimental fluids were water and air. The ranges of experimental parameters were as follows: The superficial gas velocity ranged from $0.02 \mathrm{~m} \cdot \mathrm{s}^{-1}$ to $1.00 \mathrm{~m} \cdot \mathrm{s}^{-1}$ (standard state); the superficial liquid velocity ranged from $0.01 \mathrm{~m} \cdot \mathrm{s}^{-1}$ to $1.00 \mathrm{~m} \cdot \mathrm{s}^{-1}$. The maximum relative uncertainty of superficial gas velocity, superficial liquid velocity, pressure and liquid holdup were $1.51 \%, 1.46 \%, 1.01 \%$ and $1.69 \%$, respectively.

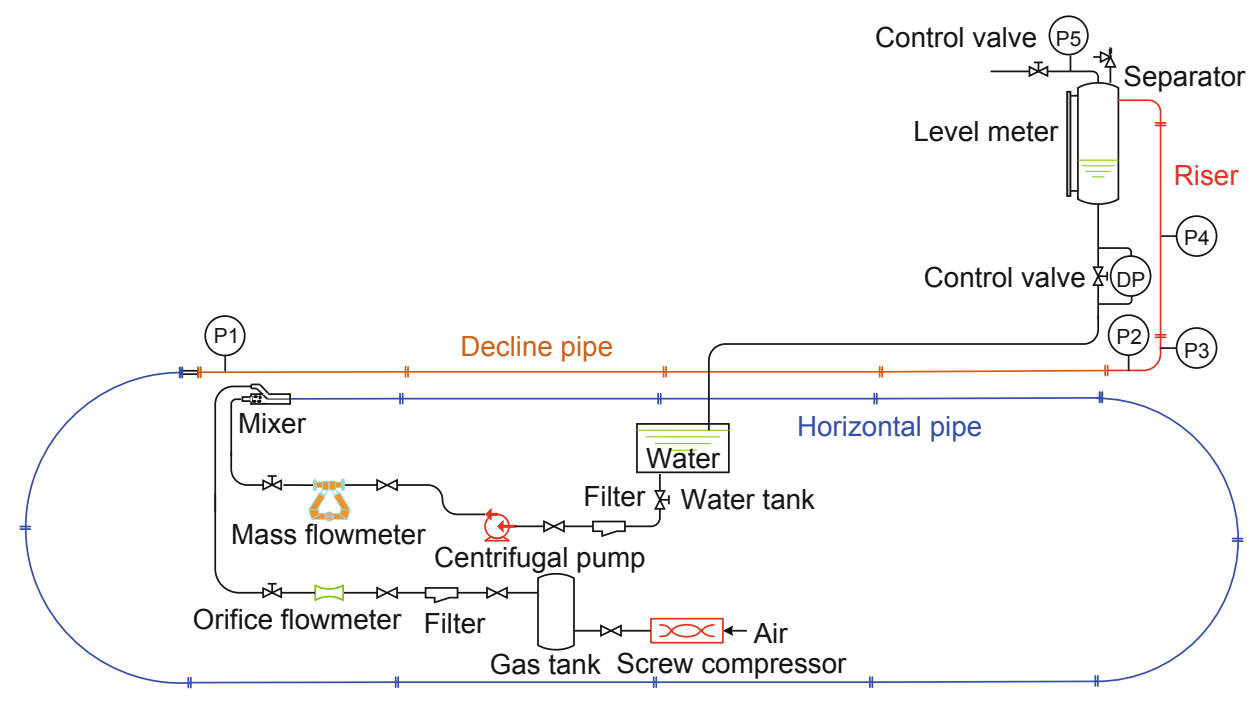

Fig. 1 Schematic diagram of the experimental system

\section{Separator control strategies}

Constant pressure control and variable pressure control are the two main strategies of separator control. In the former method, the pressure and the liquid level in the separator are separately controlled to be stabilized by different sensors and regulating valves. At present, this strategy is adopted in offshore oilfields. However, the separator remains at its original high pressure when the liquid amount suddenly decreases, which is unfavorable for the stability and recovery of the liquid level. In the latter strategy, only the liquid level is controlled, instead of pressure, by adjusting both the gas and the liquid regulating valves. When the liquid level rises, the liquid regulating valve increases its opening to discharge more liquid. Meanwhile, the gas regulating valve decreases its opening to pressurize so as to accelerate the discharge rate. When the liquid level decreases, the gas and liquid regulating valves reverse to make the level stable as soon as possible.

PID control is preferred in recent industrial constant control. The normal PID control system usually has excellent steady-state response characteristics, instead of the dynamic response characteristics. The self-tuning fuzzy PID arithmetic can autocorrect the PID parameters, including the adjustable normal PID controller and the fuzzy controller. When the deviation $e$ and the rate of change of the deviation $e c$ are inputted, the PID controller parameters $K_{\mathrm{p}}, K_{\mathrm{i}}$ and $K_{\mathrm{d}}$ are outputted. The three parameters update continuously according to the fuzzy control theory by constantly testing $e$ and $e c$. In this way, the requirements of different $e$ and $e c$ on control parameters can be met so that the controlled object can get perfect dynamic and static characteristics. Fig. 2 is the diagram of the self-tuning fuzzy PID control principle.

The fuzzy control can self-tune PID parameters. However, these parameters often vary considerably. The system stability would be reduced if they were used directly. Thus, a group of pre-setting PID parameters $K_{\mathrm{p}}^{\prime}, K_{\mathrm{i}}^{\prime}$ and $K_{\mathrm{d}}^{\prime}$ will be provided at first. Fuzzy control then self-tunes the fuzzy increments $\Delta K_{\mathrm{p}}, \Delta K_{\mathrm{i}}$ and $\Delta K_{\mathrm{d}}$ online based on PID control rules and 


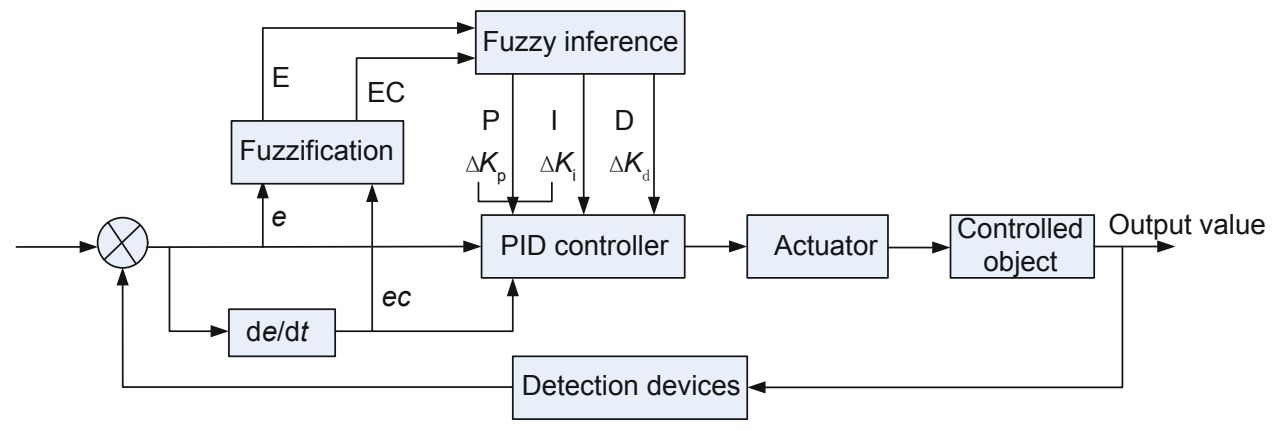

Fig. 2 Diagram of the self-tuning fuzzy PID control principle

different $|E|$ and $|E C|$. The final PID parameters $K_{\mathrm{p}}, K_{\mathrm{i}}$ and $K_{\mathrm{d}}$ are the sum of pre-setting parameters and fuzzy increments respectively. In this paper, when the PID parameters are $K_{\mathrm{p}}$ $=27.4, K_{\mathrm{i}}=9 \mathrm{~s}$ and $K_{\mathrm{d}}=2 \mathrm{~s}$, the liquid level is well controlled. And when they are $K_{\mathrm{p}}=35.0, K_{\mathrm{i}}=9.5 \mathrm{~s}$ and $K_{\mathrm{d}}=2 \mathrm{~s}$, the pressure control performs well.

As shown in Fig. 3, the pressure and liquid level in the separator are controlled at constant values according to the PID control rules in the constant pressure control strategy. The pressure transmitters on the top of the separator gather pressure signals and transmit them to the self-tuning PID control instrument for calculation. The output of valve location signals are received by the electric control valve at the gas outlet of the separator. The valve regulates pressure to the setting value by changing its opening. The constant level control has a similar control process. The magnetic flap level gauge collects level signals and transmits them to the PID control instrument for control calculation. The liquid control valve receives its output signals and changes its opening to stabilize the liquid level. The pressures are set to 0 , $50,100,150,200 \mathrm{kPa}$ while levels are set to $0,0.5,1.0$ and 1.5 $\mathrm{m}$.

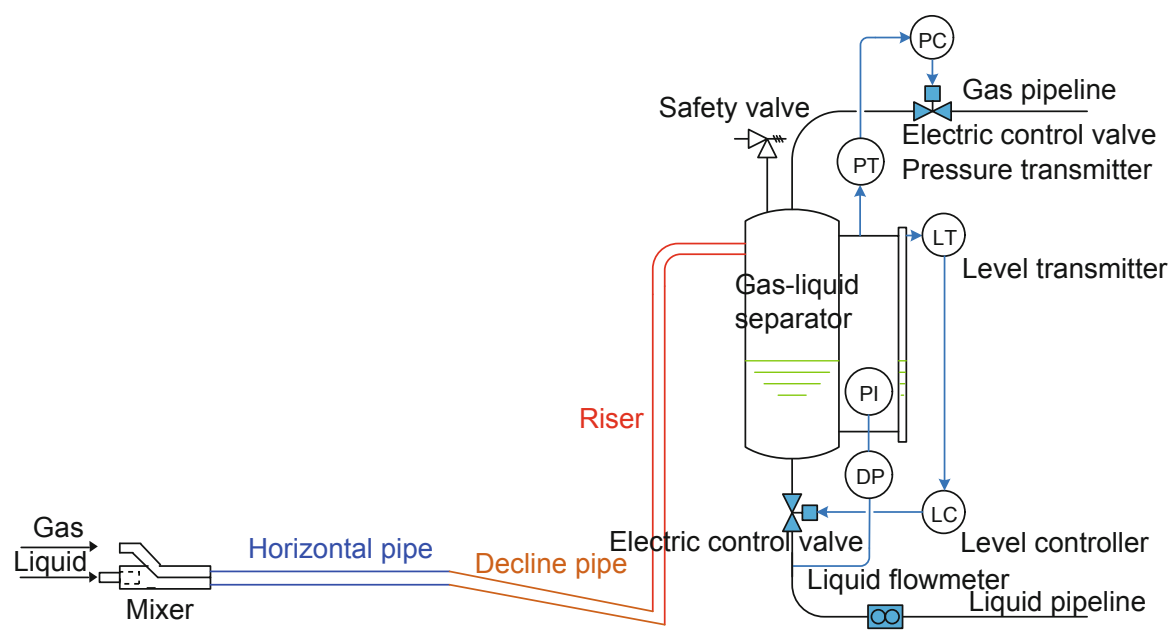

Fig. 3 Schematic diagram of constant pressure control of the separator

\section{Multiphase flow characteristics without controlling separator pressure and level}

Fig. 4 indicates the pressure fluctuation curves of five measurement points in the system in which no separator was used to control the pressure and liquid level. This figure shows that pressure fluctuated periodically. The pressure $p_{4}$ in the middle of the riser and the pressure $p_{5}$ at the top of the separator underwent sharp increases. The flow pattern under these working conditions was typical severe slugging (Luo et al, 2011).

The separator level and liquid control valve opening curves are shown in Fig. 5. When the liquid control valve was $75 \%$ open, the separator level showed periodical sudden changes. Liquid in the separator discharged smoothly at the four stages of severe slugging except blowout, leading to the

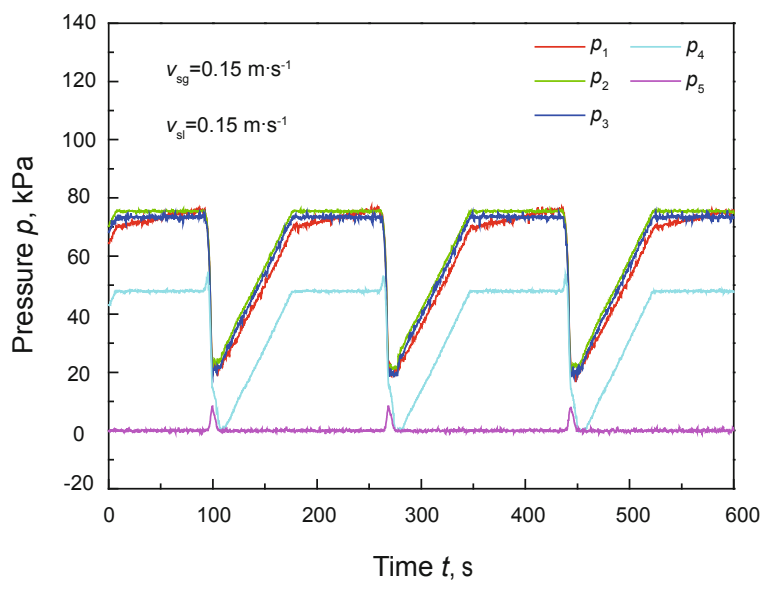

Fig. 4 Pressure fluctuation curves of the measurement points 


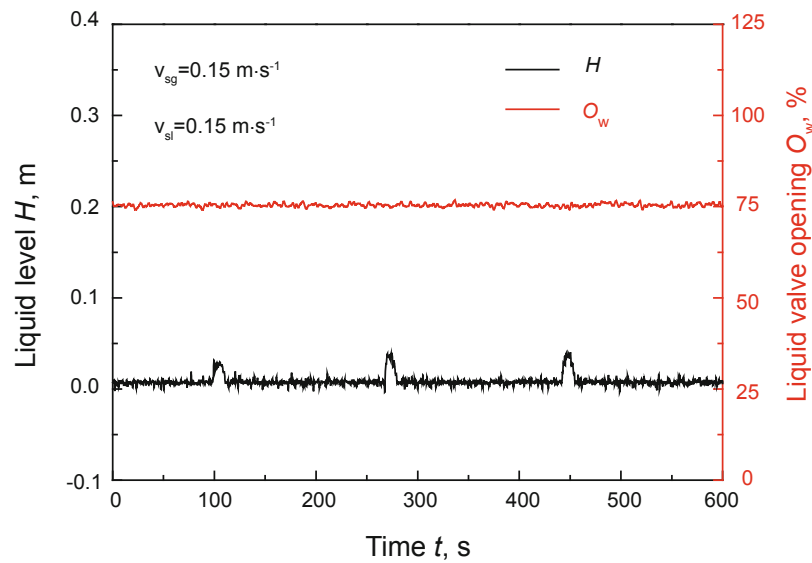

Fig. 5 Separator liquid level and liquid valve opening curves

nearly $0 \mathrm{~m}$ level. While at the blowout stage, a large amount of liquid entered the separator abruptly. However, the liquid could not be discharged at short notice. This made a sharp increase in the separator level.

Fig. 6 shows the separator pressure and gas valve opening curves. The gas control valve was $50 \%$ open and the pressure showed periodical sharp increases. This was also caused by the blowout of severe slugging.

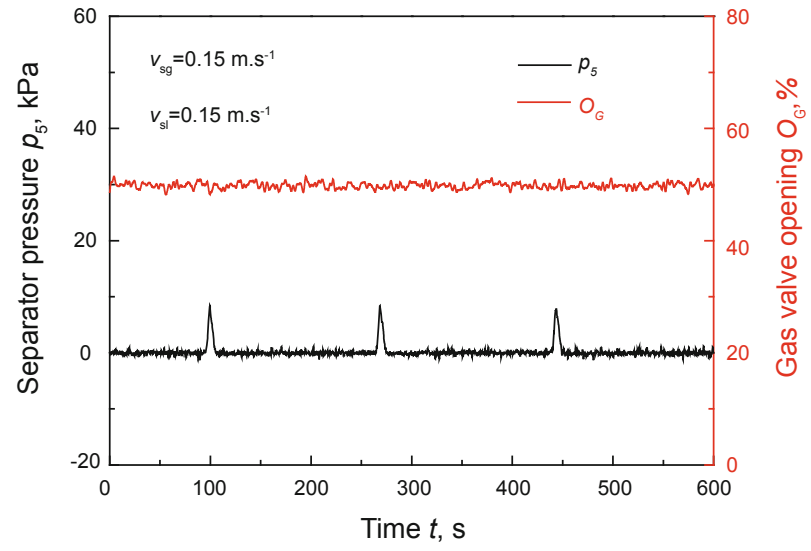

Fig. 6 Separator pressure and gas valve opening curves

Fig. 7 shows the changes of differential pressure $(\Delta p)$ of the liquid valve and flow rate with time. Both of them changed periodically for a $75 \%$ opening of the liquid control valve. This was also the result of the blowout stage of severe slugging.

\section{Effects of the control of the separator level on flow characteristics}

The curves of the separator pressure and separator liquid level in Fig. 8 were obtained on the condition that the liquid level transformed from $0 \mathrm{~m}$ to $1.5 \mathrm{~m}$ with a constant increment of $0.5 \mathrm{~m}$ and that the initial separator pressure was set to $0 \mathrm{kPa}$ when the superficial gas/liquid rate were both $0.15 \mathrm{~m} \cdot \mathrm{s}^{-1}$. The liquid level had four stable stages: $0,0.5,1.0$ and $1.5 \mathrm{~m}$. Fig. 8 indicates that the separator pressure surged periodically in all the four liquid level conditions.

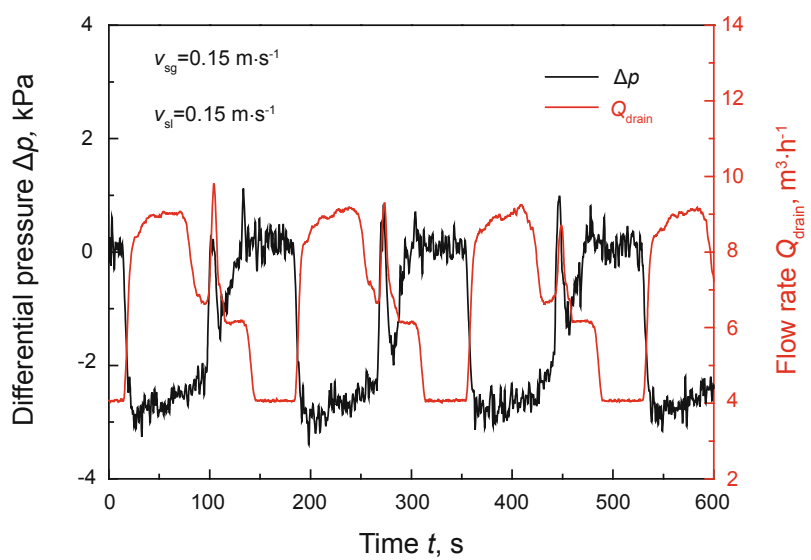

Fig. 7 Differential pressure of the liquid valve and flow rate with time

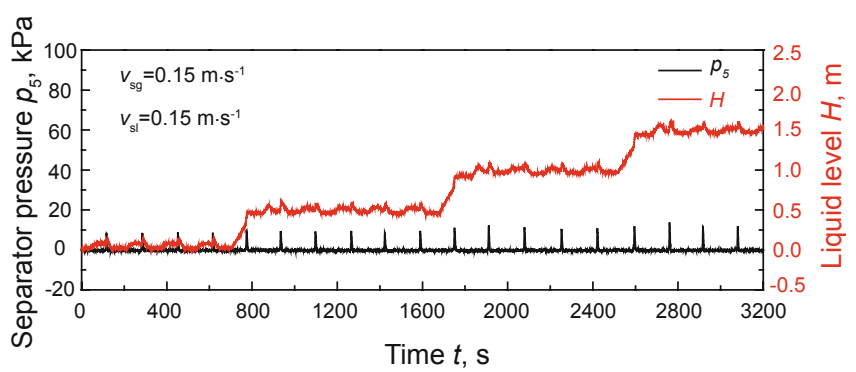

Fig. 8 Separator pressure and liquid level curves

Figs. 9 and 10 respectively indicate the relationship between the separator level as well as pressure and the opening of the liquid and gas control valve. The liquid control valve functioned periodically to stabilize the separator level. The maximum opening of the liquid control valve in the figure was $50 \%$ when the liquid level was stable. The gas control valve was set at a relative large opening (45\%) in order to guarantee the $0 \mathrm{kPa}$ separator pressure. However, the pressure had a sharp increase in each period and the extreme increment had a periodic increasing tendency with the maximum value of $10 \mathrm{kPa}$. As the separator level increased stage by stage, the gas space for buffering in the separator gradually diminished. The blowout of severe slugging resulted in a more dramatic pressure increase.

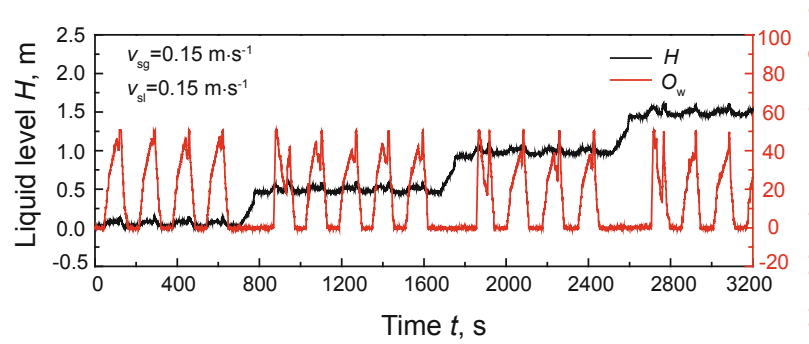

১0

$\mathrm{O}^{3}$ $\frac{0}{\prod^{\circ}}$

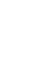

Fig. 9 Separator liquid level and liquid valve opening curves

Fig. 11 reveals the effect of the separator level control on the upstream pressure $p_{4}$ when the separator pressure was set at $0 \mathrm{kPa}$. In the process of the liquid level rising from 0 $\mathrm{m}$ to $1.5 \mathrm{~m}$ stage by stage with an increment of $0.5 \mathrm{~m}$, the 


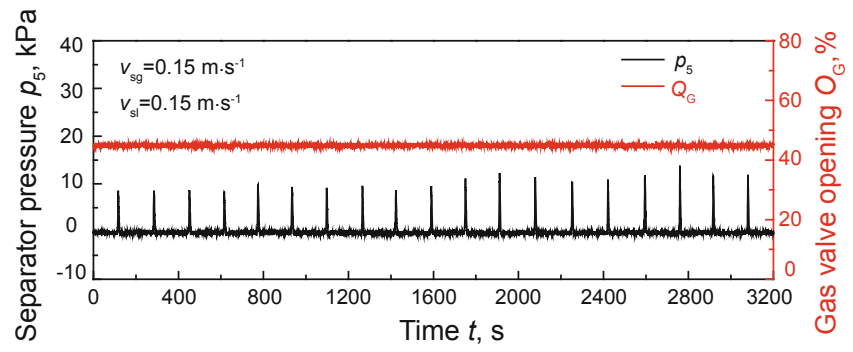

Fig. 10 Separator pressure and gas valve opening curves

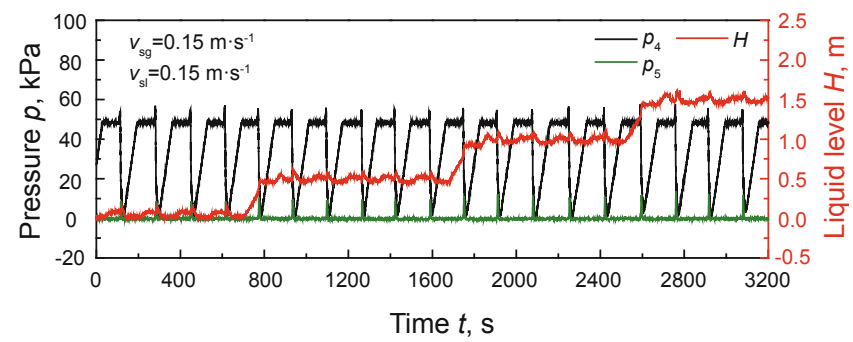

Fig. 11 Effect of the separator liquid level control on the upstream pressure

change period of pressure $p_{4}$ (PS: $p_{4}$ not only is the reflection of the periodicity characteristic in multiphase flow, but also indicates the blowout intensity in severe slugging) and the peak pressure which reflected the intensity of severe slugging blowout had no noticeable change. This manifested that the separator control alone could not effectively influence the flow characteristic of upstream multiphase flow in the system.

Curves of flow rate and the differential pressure of the liquid control valve are shown in Fig. 12. The differential pressure gradually increased and it fluctuated periodically while the amplitudes of the fluctuation remained stable. The periodical fluctuation was caused by the periodical blowout. This indirectly illustrated that the flow characteristics of upstream multiphase flow had no obvious change with the separator liquid level control alone. Discharged liquid flow rate could also be divided into four stages. The flow rate at each stage changed periodically. The period did not change dramatically. Only the maximum discharged fluid flow increased slightly. It was because the maximum discharge of the control valve increased with increasing differential pressure before and after the valve when the valve opening remained the same.

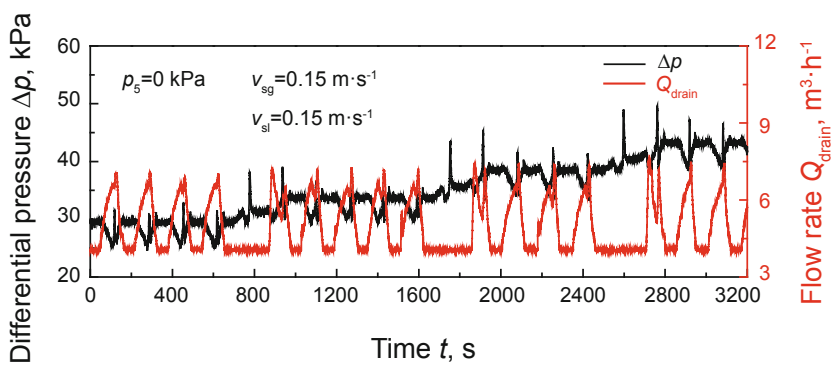

Fig. 12 Curves of flow rate and the differential pressure of liquid control valve with time

In summary, the separator control alone has no effective influence on the upstream multiphase flow. However, in the separator control strategy, the effect of the level control is closely related to the pressure control and the normal running of the downstream equipments. Thus, the separator level control is essential.

\section{Effects of the control of the pressure on flow characteristics}

Fig. 13 shows how the separator pressure and liquid level changed with time in controlling the separator pressure. The separator liquid level fluctuated periodically around $0.5 \mathrm{~m}$ while the pressure was controlled at five set values $0,50,100$, 150 and $200 \mathrm{kPa}$. The curve of separator level $H$ indicates that the maximum level fluctuation decreased with increasing separator pressure. This demonstrates that the amount of liquid flushing into the separator gradually decreased when the blowout occurred. The intensity of blowout was controlled gradually.

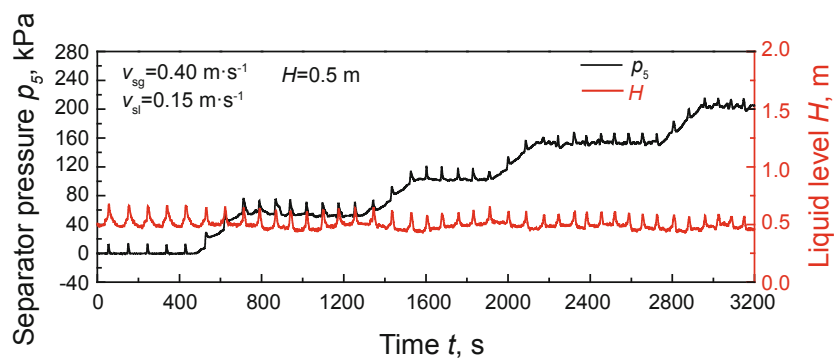

Fig. 13 Separator pressure and separator liquid level curves with time

Figs. 14 and 15 show the relationship between the separator level and the liquid valve opening and that between the pressure and the gas valve opening. As is shown in Fig. 14 , the liquid valve was regulated periodically to maintain a stable level at $0.5 \mathrm{~m}$ and the maximum opening of it decreased gradually. The change period of the valve opening also decreased slightly. For one reason, when the pressure after the valve was constant, the pressure before the valve increased with the increasing separator pressure, and the differential pressure before and after the valve increased correspondingly. For another, the increased pressure not only weakened the blowout intensity but also reduced the liquid amount of blowout so that severe slugging was inhibited. This was also the reason leading to the decrease in the maximum opening of the liquid valve and its change period. In Fig. 15, the gas control valve functioned frequently except for $0 \mathrm{kPa}$ separator pressure to stabilize the five set pressures ranging

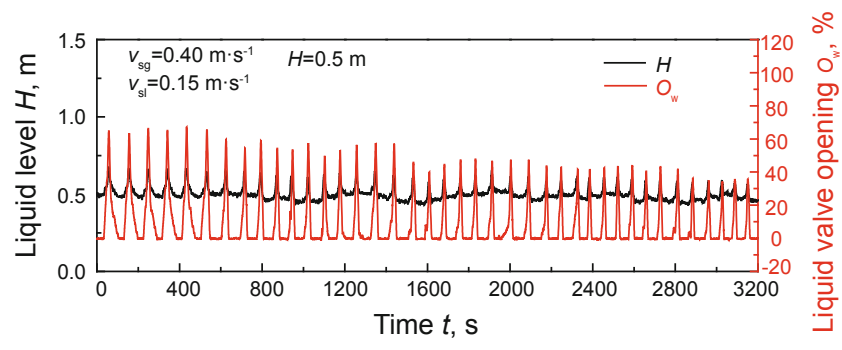

Fig. 14 The relationship between the separator liquid level and the liquid valve opening 


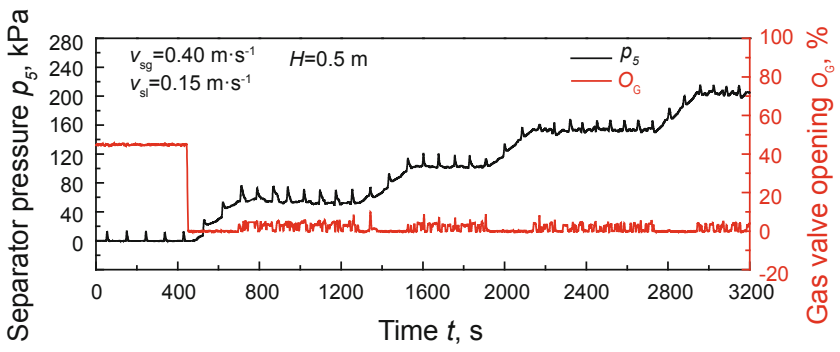

Fig. 15 The relationship between the separator pressure and the gas valve opening

from 0 to $200 \mathrm{kPa}$ with an increment of $50 \mathrm{kPa}$. The opening range of the gas valve was relatively smaller than that of the liquid valve.

The difference of the pressure $p_{4}$ and the separator pressure $p_{5}$ is defined as relative pressure $p_{4}^{*}\left(p_{4}^{*}=p_{4}-p_{5}\right)$. This could directly reflect the effect of the separator pressure change on the upstream pressure characteristics. The effect of the separator pressure on $p_{4}^{*}$ when the superficial gas rate was $0.4 \mathrm{~m} \cdot \mathrm{s}^{-1}$ and the superficial liquid rate was $0.15 \mathrm{~m} \cdot \mathrm{s}^{-1}$ with the $0.5 \mathrm{~m}$ liquid level is shown in Fig. 16.

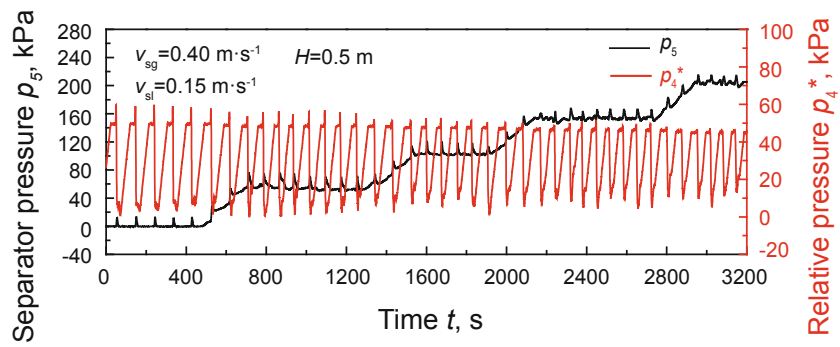

Fig. 16 The effect of the separator pressure change on the relative pressure $p_{4}^{*}$

As shown in Fig. 16, the fluctuation amplitude of $p^{*}{ }_{4}$ and the fluctuation period gradually decreased when the separator pressure changed from 0 to $200 \mathrm{kPa}$ stage by stage with an increment of $50 \mathrm{kPa}$. The peak pressure gradually decreased to some degree. The vibration of the upstream pipes during the slug blowing out reduced remarkably. All these manifest that severe slugging was gradually inhibited.

Curves of the liquid holdup $H L_{1}$ at the bottom of the declined pipe and $H L_{2}$ in the middle of the riser are shown in Fig. 17. $H L_{1}$ and $H \mathrm{~L}_{2}$ fluctuated periodically when the separator pressure changed from $0 \mathrm{kPa}$ to $200 \mathrm{kPa}$ by stages with increments of $50 \mathrm{kPa}$. However, the periods were gradually shortened. Meanwhile, the minimum liquid holdup of $H L_{2}$ had a rising tendency. The power of gas in the riser to penetrate the liquid plug was enhanced during severe slugging blowing out as the separator pressure increased, resulting in the intensive gas/liquid slip. The gas amount in the long liquid plug decreased as well. On the other hand, the increasing pressure in the separator led to weaker blowouts. The long gas plug quickly flowed through the riser, and then tended to morph into short and slowly flowing gas bubbles.

The fluid flow rate, pressure difference and the turndown ratio of the control valve changing with time are shown in Fig. 18. The pressure difference of the liquid control valve
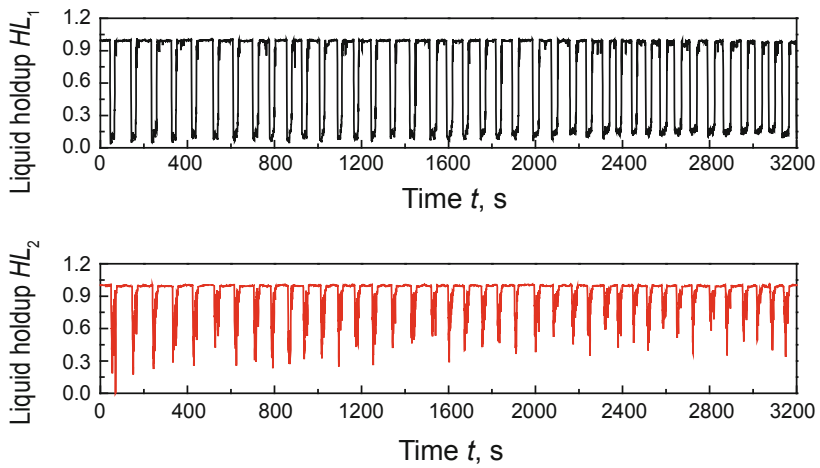

Fig. 17 The effect of the separator pressure change on the liquid holdups $H L_{1}$ and $H L_{2}$

functioned periodically and its maximum opening decreased stage by stage. The discharged fluid flow rate presented a decreasing periodicity but the maximum liquid amount of the first stage was slightly less than that of the other four stages. One reason was that the increasing pressure difference led to the increase in the fluid flow rate with the constant opening. Another was that the decrease in the opening directly caused a decreased fluid flow rate with an identical pressure difference. These two factors decided the final fluid flow rate.
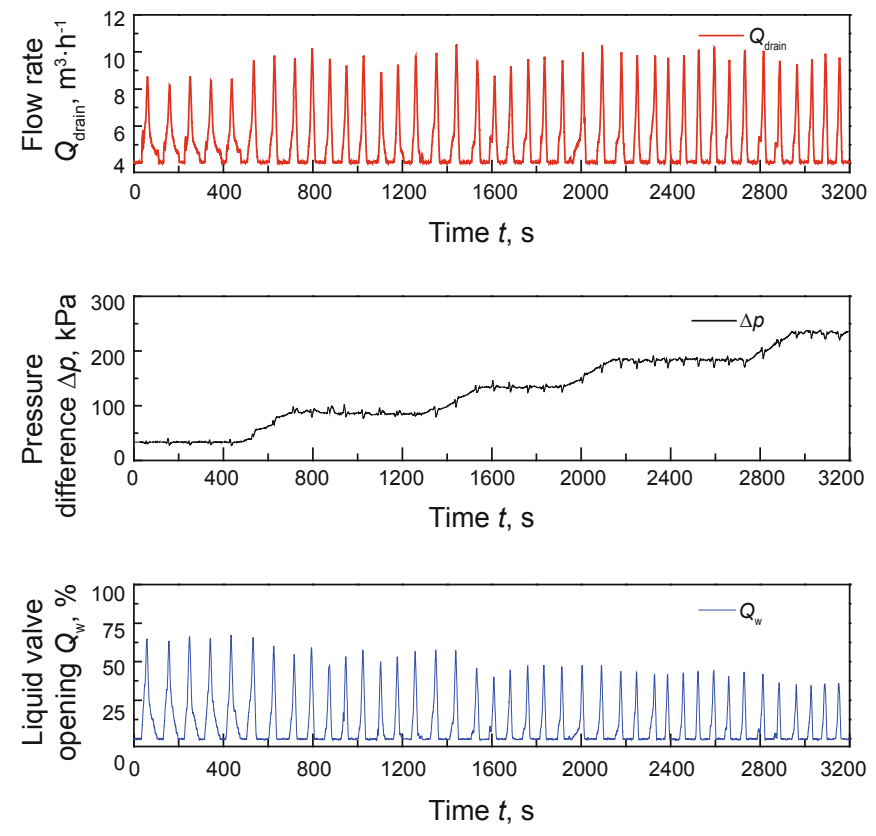

Fig. 18 The fluid flow rate, pressure difference and the turndown ratio of the control valve changing with time

Three typical conditions in severe slugging were chosen to study the effects of the separator control on flow characteristics. The liquid level was set at constant $0.5 \mathrm{~m}$ and the pressure in the separator was controlled at five stages, which were $0,50,100,150$ and $200 \mathrm{kPa}$, separately. Three complete periods were needed in each stage.

Fig. 19 indicates the curves of the extreme values of $p_{4}^{*}$ changing over the separator pressure. The maximum values of $p_{4}^{*}$ decreased with increasing separator pressure while the minimum values increased. This showed that the fluctuation 
of $p_{4}^{*}$ eased with the increasing separator pressure. The severe slugging was inhibited gradually. Nonetheless, as shown in Fig. 19, the extreme values of $p_{4}^{*}$ (especially minimum values) of the three conditions changed differently under the same control strategy. The minimum value changed most with smaller superficial gas rate and larger superficial liquid rate while it changed least with larger superficial gas rate and smaller superficial liquid rate. The fluctuation of $p_{4}^{*}$ reflected the effects of the separator control on severe slugging. The severe slugging with smaller superficial gas rate and larger superficial liquid rate was inhibited effectively under constant pressure control. However, in the situation of larger superficial gas rate and smaller superficial liquid rate, the inhibition was weak. The relative strength of superficial gas/ liquid rate significantly influenced the inhibition of severe slugging under constant pressure control.

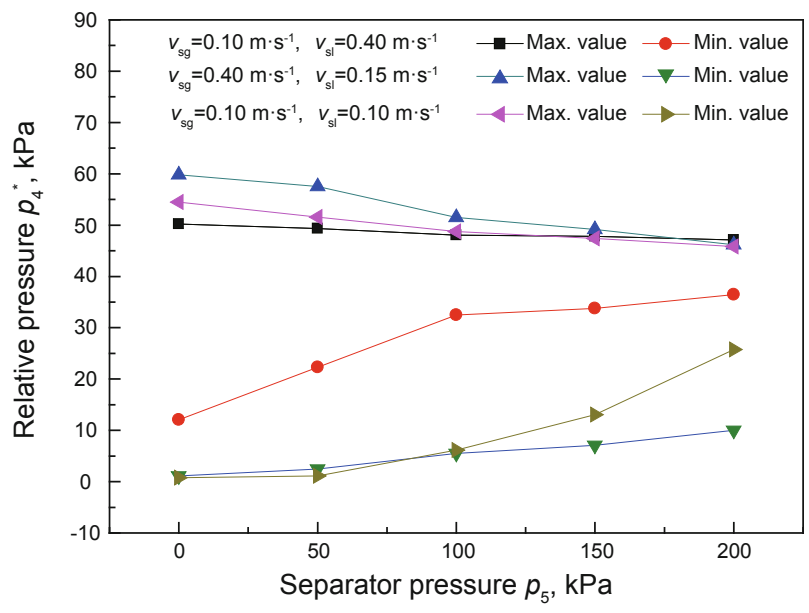

Fig. 19 Extreme value of $p_{4}^{*}$ versus the separator pressure curves in different types of severe slugging

Three typical conditions in severe slugging were chosen to study the effects of the separator control on the inhibition of severe slugging with different superficial gas/liquid rates. The extreme values of $p_{4}^{*}$ changing over the separator pressure are shown in Fig. 20. The maximum values of $p_{4}^{*}$ decreased with increasing separator pressure while the minimum values increased. Curves of the maximum pressure indicate nearly the same change of the maximum values with three groups of the superficial gas/liquid rate, which illustrated that the separator pressure control had an identical effect on severe slugging conditions with different superficial gas rates. As is shown in the curves of the minimum pressure, the rate of increase of the minimum pressure was decreasing with increasing superficial gas/liquid rate. When the pressure in the separator was low, the drag effect of the pressure difference caused by gas expansion after blowout on fluid in the declined pipe was small. As a result, the liquid recharge rate in the riser was determined by the inherent superficial liquid rate. Therefore, the liquid recharge rate was much larger with a higher superficial liquid rate, which brought about a relatively higher minimum pressure. When the separator pressure was high, the drag effect of the pressure difference on fluid in the declined pipe was increased. The liquid recharge rate in the

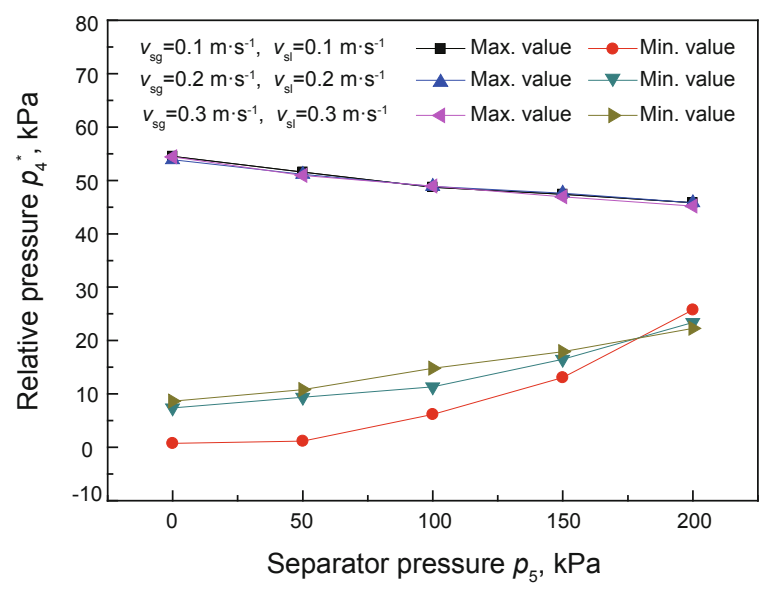

Fig. 20 Extreme value of $p_{4}^{*}$ versus the separator pressure curves in different types of severe slugging

riser was mainly determined by the drag force caused by the pressure difference. The influence of the superficial liquid rate was weak and the three minimum pressures approached each other. The slip intensity was weak at low separator pressure while it was strong at high separator pressure. This was also one of the reasons for the phenomena above.

In summary, the absolute values of the superficial gas/ liquid rate have no significant impact on the separator control to inhibit severe slugging with identical superficial gas/ liquid rates. They just slightly influence the recharge rate after blowing out. The influence gradually weakened as the separator pressure increased.

\section{Conclusions}

1) The separator liquid level and pressure in severe slugging are precisely controlled under the separator control strategy.

2) The separator liquid level control alone does not have an effective impact on the upstream multiphase flow. However, it is closely related to the separator pressure control and can prevent the separator from overflowing.

3) When the separator pressure increases, the peak pressure in the riser apparently diminishes, and the fluctuation amplitude of pressure gradually decreases. Hence, the upstream severe slugging is inhibited. During the slug blowing out, the gas/liquid slipping in the riser intensifies. The long gas plug quickly flows through the riser, and then tends to morph into short and slowly flowing gas bubbles.

4) The inhibiting effect of pressure control strategy on the upstream severe slugging is related to the relative size of the superficial gas/liquid rate.

\section{References}

Almeida A R and Gonçalves M A L. Venturi for severe slugging elimination. Proceedings of the 9th International Conference on Multiphase Production, BHRG. 1999. 149-158

Almeida A R, Lima M D A and Gonçalves M A L. Device and method for eliminating severe slugging in multiphase stream flow lines. US Patent, 6041803, March 28, 2000

Barbuto F A. Method and apparatus for eliminating severe slug in multiphase flow subsea lines. US Patent 5478504, December 26, 1995 
Godhavn J M, Fard M P and Fuchs P H. New slug control strategies, tuning rules and experimental results. Journal of Process Control. 2005. 15(5): 547-557

Hassanein T and Fairhurst P. Challenges in the mechanical and hydraulic aspects of riser design for deep water development. Off-shore Pipeline Technology Conference, Oslo Norway, 1988

Havre K and Dalsmo M. Active feedback control as the solution to severe slugging. Paper SPE 71540 presented at SPE Annual Technical Conference and Exhibition, 30 September October 2001, New Orleans, Louisiana

Henriot V. Simulation of process to control severe slugging: application to the Dunbar pipeline. Paper SPE56461 presented at SPE Annual Technical Conference and Exhibition, 3-6 October 1999, Houston, Texas

Hollenberg J, DeWolf S and Meiring W. A method to suppress severe slugging in flow line riser systems. Proc. 7th Int. Conf. on Multiphase Technology Conference, Cannes, France, 1995

Jansen F E. Elimination of Severe Slugging in a Pipeline-Riser System. Tulsa: University of Tulsa, 1990

Johal K S. An alternative economic method to riser-base gas lift for deep water subsea oil/gas field developments. Paper SPE 84947 presented at Offshore Europe, 9-12 September 1997, Aberdeen, United Kingdom

Kaasa $\varnothing$. A subsea slug catcher toprevent severe slugging. 6th Underwater Technology International Conference, Bergen, Norway, 1990

Kovalev K, Cruickshank A and Purvis J. The slug suppression system in operation. Paper SPE 38541 presented at Offshore Europe, 2-5 September 2003, Aberdeen, United Kingdom

Li X P, Gong J and Shen J P. Experimental study of a method for controlling the severe slugging in risers. China Offshore Oil and Gas. 2005. 17(6): 416-420 (in Chinese)

Liu M E, Li Q P, An W J, et al. A one-dimensional transient model of severe slugging in risers. China Offshore Oil and Gas. 2007. 19(2): 125-130 (in Chinese)

Luo X M, He L M and Lv Y L. Fluctuation characteristic of slug flow holdup in horizontal pipes. Journal of the College of Chemical Engineering. 2009. 23(4): 719-723 (in Chinese)

Luo X M, He L M and Ma H W. Flow pattern and pressure fluctuation of severe slugging in pipeline-riser system. Chinese Journal of Chemical Engineering, 2011. 19(1): 26-32 (in Chinese)

Lv Y L, He L M, Niu D G, et al. Self-control pump suction method to eliminate severe slugging. Journal of Chemical Engineering. 2011.
62(7): 1846-1851 (in Chinese)

Ma H W, Ren Y L, Li H Y, et al. Experiment and model of the bypass tube method to eliminate severe slugging. Journal of Chemical Engineering. 2010. 61(10): 2552-2557 (in Chinese)

Meng $\mathrm{W} \mathrm{H}$ and Zhang $\mathrm{J}$ J. Modeling and mitigation of severe riser slugging: a case study. Paper SPE 71564 presented at SPE Annual Technical Conference and Exhibition, 30 September-3 October 2001, New Orleans, Louisiana

Sarica $\mathrm{C}$ and Tengesdal J. A new technique to eliminate severe slugging in pipeline/riser systems. Paper SPE 63185 presented at SPE Annual Technical Conference and Exhibition, 1-4 October 2000, Dallas, Texas

Schmidt Z, Brill J P and Beggs H D. Choking can eliminate severe pipeline slugging. Oil and Gas Journal. 1979. 12: 230-238

Song S and Kouba G. Fluids transport optimization using seabed separation. Journal of Energy Resources Technology. 2000. 122(3): 105-109

Storkaas E and Skogestad S. Stabilization of severe slugging based on a low-dimensional nonlinear model. Paper 259e presented at AIChE Annual Meeting, 2002, Indianapolis, USA

Storkaas E, Skogestad S and Godhavn J M. A low-dimensional dynamic model of severe slugging for control design and analysis. Paper presented at 11th International Conference on Multiphase flow (Multiphase03), 117-133, 2003, Trondheim, Norway

Sun H Y, Zhu L, Hou Y, et al. The study and control of severe slugging in pipelines or risers. Oil-Gas Field Surface Engineering. 2004. 23(11): 23-25 (in Chinese)

Tengesdal J, Thompson L and Sarica C. A design approach for a "SelfLifting" method to eliminate severe slugging in offshore production systems. SPE Production \& Facilities. 2005. 20(3): 201-206

Wang X, Guo L J, Zhang X M, et al. Experimental study of severe slugging in gathering pipeline risers. Journal of Engineering Thermophysics. 2005. 26(5): 799-801 (in Chinese)

Wang X and Guo L J. Experiment and theoretical simulation of severe slugging in the riser system of gathering pipelines. Journal of Engineering Thermophysics. 2006. 27(4): 611-614 (in Chinese)

Wang X. Study of Two Phase and Multiphase Slug Flow in Horizontal Pipes as well as Severe Slugging in Gathering and Transportation Rising Pipe Systems. Ph.D. Dissertation. Xi'an Jiao Tong University, 2006 (in Chinese)

Zhao Y C, Peng H X, Wu D L, et al. The research process of the methods to eliminate severe slugging. Pipeline Technology and Equipment. 2004. (2): 1-7 (in Chinese) 